\title{
INTERGROUP LEADERSHIP IN ORGANIZATIONS: LEADING ACROSS GROUP AND ORGANIZATIONAL BOUNDARIES
}

\author{
MICHAEL A. HOGG \\ Claremont Graduate University \\ DAAN VAN KNIPPENBERG \\ Erasmus University Rotterdam \\ DAVID E. RAST, III \\ Claremont Groduate University
}

\begin{abstract}
Intergroup leadership-leadership of collaborative performance of different organizational groups or organizations-is associated with unique intergroup challenges that are not addressed by traditional leadership theories. To address this lacuna, we describe a theory of intergroup leadership. Firmly grounded in research on social identity and intergroup relations, the theory proposes that effective intergroup performance rests on the leader's ability to construct an intergroup relational identity. We describe key leadership actions to establish such an identity.
\end{abstract}

Leadership is a key issue in management research and practice. Questions revolving around issues of effective leadership-leaders' success in mobilizing and motivating followers (Bass, 1990; Yukl, 2010)_have been on the behavioral research agenda for over a hundred years (Judge, Bono, Ilies, \& Gerhardt, 2002). Yet leadership research has scarcely engaged with what is arguably one of the bigger challenges of leadership in organizations: leadership across group and organizational boundaries, known as intergroup leadership (Pittinsky, 2009; Pittinsky \& Simon, 2007).

Leadership is typically understood as taking place in a situation where leaders and followers share a formal group membership (i.e., the CEO leads the members of the organization, the team leader leads the members of the team, etc.) and other group memberships do not come into play, are of little importance to the leadership situation, or are merely seen as nuisance factors. There are, however, many situations in which leadership is required to influence collaborative efforts of different formal groups within organizations (e.g., interdepartmental cooperation; Brett \& Rognes, 1986; Kromer, 1991; Mohrman, Cohen, \& Mohrman, 1995), as well as between organizations (e.g., joint ventures; Hambrick, Li, Xin, \& Tsui, 2001). Increasingly, such intergroup efforts also cross national, cultural, ethnic, and religious boundaries, posing further challenges to effective intergroup collaborations. In such situations, different group memberships are not to be downplayed or ignored - they are the very reason for the organizational and leadership efforts in the first place. Indeed, effective intergroup leadership is required to realize the potential benefits of intergroup collaboration and to prevent disruptive conflicts between groups.

To illustrate intergroup leadership challenges, let us consider the following three scenarios. First, an inner-city school is taking part in a city-wide canned food drive and competition. To succeed, the school's principal must coordinate the efforts of the teachers, as a group, and the students, who are represented by the student governance group. The two groups have distinct identities and a history of "conflict" with one another within the school. But for the school to be competitive in the drive, the groups need to work together cooperatively. Second, within a hospital the group of nurses and the group of doctors have distinct identities and practices and occupy separate "quarters." Both groups consider themselves to be the essential part of the hospital and have a history of conflict over pay, conditions, recognition, and "voice" in hospital governance. The hospital's director realizes that this oppositional intergroup relationship intrudes on medical interactions and 
practices (there are heated arguments, intransigent disagreements, lack of respect, and so forth) and, thus, compromises the hospital's mission to provide high-quality patient care. Third, within a scholarly press the main groups are the "books" and "journals" divisions. These groups serve different purposes, are housed in different buildings, have separate administrative and leadership structures, rarely interact across group boundaries, and have distinct identities and cultures that they are each proud of and fiercely defend and promote. This arrangement has a long history-members of the books division feel they are favored and engage in the company's core business, whereas members of the journals division feel they are underrecognized but are the profitable future of the company. The press's new director needs to make these "warring" factions realize that for the company to thrive and overcome fiscal and market challenges, they must improve intergroup relations and work together cooperatively in a new world of electronic publishing.

These scenarios are not uncommon within and between organizations and groups. However, current leadership models (e.g., focusing on personality [Judge et al., 2002], social exchange [Graen \& Uhl-Bien, 1995], charismatictransformational leadership [Bass, 1985; Conger \& Kanungo, 1987], social identity [Hogg \& van Knippenberg, 2003; Lord, Brown, \& Freiberg, 1999], or team leadership [Day, Gronn, \& Salas, 2004; Pearce \& Sims, 2000]) were not developed with such leadership situations in mind. As a consequence, they are not well equipped to explain effective intergroup leadership. To properly understand intergroup leadership, what is required is an account of intergroup leadership that is fully attuned to the intergroup dynamics of such situations-a model that builds on the science of intergroup relations and intergroup behavior and tightly articulates this with the science of leadership. In this article we present such a model. The key premise is that organizations serve identity functions for their members and are crucibles of intergroup relations and that leadership theory, therefore, benefits from explicitly confronting both the intergroup and identity dimensions of organizations.

Intergroup collaboration, and hence intergroup leadership, is very much on issue of identity. Group and organizational memberships are an important source of social identity; they in- vite cognitive-evaluative representation of the self in terms of attributes of and membership in the group or organization (i.e., "we"; Ashforth \& Mael, 1989; Hogg \& Terry, 2000; Sluss \& Ashforth, 2007; Tajfel \& Turner, 1979; Turner, Hogg, Oakes, Reicher, \& Wetherell, 1987). Social identities are pivotal in the development of intergroup relations inside and outside organizations (Brewer \& Brown, 1998; van Knippenberg, 2003). Effective leadership, too, is contingent on social identity dynamics (Hogg, 2001, 2008; Hogg \& van Knippenberg, 2003; Lord et al., 1999; Shamir, House, \& Arthur, 1993; van Knippenberg \& Hogg, 2003). In accordance with these insights, we ground our anclysis of intergroup leadership in on understanding of these social identity dynamics. We first briefly discuss how neither leadership theory nor research in intergroup relations has really engaged with the notion of intergroup leadership. We then outline how the traditional intragroup understanding of leadership can be complemented by a social identity analysis of intergroup leadership, building on the state of the science in research on intergroup relations to identify the key challenges that are on the agenda for intergroup leadership.

This analysis culminates in a conceptual model of intergroup leadership, the core elements of which are captured in a series of specific propositions. Central to our analysis is the general proposition that intergroup leadership effectiveness (i.e., in terms of stimulating the quality of intergroup collaborative performance) revolves around leaders' ability to engender a sense of intergroup relational identity (i.e., selfdefinition in terms of one's group membership that incorporates the group's relationship with another group as part of the group's identity). This focus on intergroup relational identity has markedly different leadership implications than the more "traditional" focus on creating a shared superordinate identity (see van Knippenberg, van Knippenberg, De Cremer, \& Hogg, 2004) and thus raises unique questions about the leadership required to engender such an intergroup relational identity-questions we also address in the current analysis.

The main contribution of our analysis is advancing a theoretical model of intergroup leadership. However, our analysis also makes contributions beyond the field of intergroup leadership. The conceptualization of intergroup relational identity is a unique contribution and 
an extension of fundamental theory not only on leadership but also on social identity and intergroup relations. Thus, our analysis speaks both to intergroup leadership in organizations and to research on social identity and intergroup relations more generally by suggesting that research has overlooked one of the more promising alternatives in successfully managing intergroup relations: the creation of a sense of intergroup relational identity.

\section{THE CHALLENGE OF INTERGROUP LEADERSHIP}

\section{The Need for Intergroup Leadership}

Intergroup leadership as we conceptualize it here refers to leadership of collaborative efforts of more than one formal group or organization toward a joint goal, in which the purpose of the collaboration relies on the presence of these groups or organizations. This definition explicitly identifies formal organizational groups or organizations-for instance, "books" and "journals" in our press example. It does not include leadership of other identity groups in organizations (e.g., demographic groups), as that would fall under the rubric of "leadership of (intragroup) diversity" and would not involve leadership with the purpose of collaboration between formal organizational groups. In focusing on formal organizational groups, our approach has different boundary conditions than do approaches that focus on demographic diversityfor example, Alderfer's (1997) and Alderfer and Smith's (1982) embedded intergroup relations theory has a focus on race and, to some extent, gender relations within organizations and between individuals.

The effectiveness of intergroup leadership is thus also understood in terms of collaborative intergroup performance (e.g., Richter, West, van Dick, \& Dawson, 2006). Following Richter and colleagues, we view intergroup performance as the collaborative performance of two or more formal organizational groups (or organizations) on tasks that require the concerted efforts of both/all groups. Effective intergroup leadership is therefore indicated by successful intergroup performance of the collaborative relationship targeted by the leadership-just as individual or group performance is typically seen as the primary indicator of interpersonal or intragroup leadership effectiveness (Kaiser, Hogan, \& Craig, 2008). Intergroup performance, and hence intergroup leadership effectiveness, is thus understood in terms of behavioral outcomes, not in terms of group member psychological states or subjective experiences, as sometimes also is the case in research on leadership effectiveness-it is understood as the objectively identifiable product of intergroup collaboration.

Intergroup leadership is not typically recognized as a domain of or challenge for leadership, perhaps reflecting the more general tendency in management research to overlook the importance of intergroup relations (Richter et al., 2006; van Knippenberg, 2003). Once the lens of intergroup leadership is adopted, however, it is not difficult to identify a host of situations that would require intergroup leadership as conceptualized here-for example, the school, hospital, and press examples described above.

Whether they are called workgroups, teams, departments, business units, or something else, such groups are the basic building blocks of organizations. In many respects, organizations are collections of interrelated groups more than collections of separate individuals. In recognition of this, workgroups and teams are a significant focus of management research (Cohen \& Bailey, 1997; Ilgen, Hollenbeck, Johnson, \& Jundt, 2005).

Equally important to organizational functioning, however, are effective coordination and effective cooperation between such organizational units. High-quality organizational performance requires collaboration between organizational groups (Blake, Shepard, \& Mouton, 1964; Brett \& Rognes, 1986). Yet effective and productive intergroup collaboration is not selfevident. Organizational groups may, for instance, compete for scarce organizational resources (Pfeffer \& Salancik, 1977; Pondy, 1967) or emphasize different aspects of the collaborative enterprise (e.g., making a sale versus meeting production targets in sales-production coordination efforts). Such tensions between organizational groups may invite groups to focus on their own self-interest and adopt a competitive stance against other organizational groups, to the obvious detriment of effective intergroup collaboration and overall organizational functioning (Kramer, 1991). Here, then, lies a challenge for organizational leadership: effective intergroup leadership is called for to transform 
subgroup self-interest and detrimental competition between groups into collaboration and cooperation that optimize intergroup performance.

Just as organizational groups do not function in isolation, neither do organizations themselves. Organizations frequently collaborate and join forces in pursuit of desired outcomes. Intergroup leadership challenges also abound in such collaborations between organizations (Crosby \& Bryson, 2010). Hambrick and colleagues have, for instance, outlined how in international joint ventures intergroup tensions between the different organizations, or representatives acting on behalf of the organizations, may emerge (Hambrick et al., 2001; Li \& Hambrick, 2005). Effectively dealing with these tensions seems critical to the success of such joint ventures.

Interorganizational tensions loom even larger in mergers and acquisitions, which are often less successful than anticipated (Cortwright \& Schoenberg, 2006; King, Dalton, Daily, \& Covin, 2004). Intergroup clashes between organizational cultures are an oft-quoted source of such merger failure (Ullrich \& van Dick, 2007). In our conceptualization mergers and acquisitions are no longer cases for intergroup leadership if and when the premerger organizational boundaries are dissolved, but there are clear intergroup leadership challenges in the earlier phases of the merger or acquisition. Moreover, many merged organizations maintain premerger organizational boundaries to a substantial extent long after the merger (e.g., maintaining separate brands and separate offices). In such cases, managing intergroup relationships between merger partners remains a significant challenge for intergroup leadership, even after the formal merger has occurred.

Therefore, it seems reasonable to conclude that there are many situations in the day-to-day life of workgroups and organizations that require intergroup leadership. However, despite a long history of research on how leaders are able to influence followers, intergroup leadership has not been on the agenda of leadership research. Leadership research has identified a large variety of factors involved in leadership effectiveness, including the leader's personality (Judge et al., 2002) or behavioral style (Judge, Piccolo, \& Ilies, 2004), leader-follower relationships (Graen \& Uhl-Bien, 1995; Ospina \& Foldy, 2010), the charismatic and transformational qualities of leaders (Bass, 1985; Conger \& Kanungo, 1987; House, 1977; Shamir et al., 1993), the leader's ability to connect with followers' social identity (Hogg \& van Knippenberg, 2003; Lord et al., 1999), leader fairness (van Knippenberg, De Cremer, \& van Knippenberg, 2007), and leadership's ability to change and develop team processes (Day et al., 2004; Pearce \& Sims, 2000). Regardless of their emphasis, however, these analyses have not engaged with the intergroup nature of many leadership situations, and the specific challenges that intergroup situations pose are typically neither discussed nor acknowledged in leadership research.

Initially, research on diversity and crosscultural management may appear to be exceptions, but closer inspection shows that these focus on intragroup processes. Diversity researchers have long recognized the relevance of intergroup relations theory, viewing diverse teams as bringing together members of different backgrounds (e.g., ethnic, gender, functional specialization) within one team and proposing that people may be biased against different others based on the perception that they belong to another identity group (van Knippenberg \& Schippers, 2007; Williams \& O'Reilly, 1998). The emerging interest in leadership in these situations is framed by the proposition that in order to motivate better performance, such leaders need to create a shared team identity that distracts attention from diversity-based groupings-for instance, through transformational leadership (Kearney \& Gebert, 2009; Shin \& Zhou, 2007). Related to this, in research on crosscultural management, scholars have focused on one particularly challenging form of diversityhow to manage teams and organizations that are diverse in terms of cultural background (Gannon \& Newman, 2002; Thomas, 2008). Cultural diversity is particularly prone to communication problems and misunderstandings that make negative reactions based on cultural group membership more likely. The leadership challenge in these situations is characterized as being the same as for diverse groups and organizations in general (Dalton \& Chrobot-Mason, 2007; Smith \& Peterson, 2002; cf. Alderfer \& Smith, 1982).

Ultimately, these analyses focus on intragroup leadership-situations in which members from diverse backgrounds should function together on the basis of their membership in the 
overarching team or organization, rather than as distinct and separate groups working in collaboration. The emphasis, in such situations, on leaders' need to create a shared identity in order to provide effective leadership for a unified group (intragroup leadership) is valid (Kearney \& Gebert, 2009; cf. van Knippenberg et al., 2004), but research on intergroup relations suggests that the story is a great deal more complicated for intergroup leadership.

\section{The Leadership Challenge: Obstacles to Successful Intergroup Collaboration}

One of the most robust findings from research on intergroup behavior is that groups define who we are, and therefore groups strive to be separate from and superior to relevant outgroups (Abrams \& Hogg, 2010; Dovidio \& Gaertner, 2010; Tajfel \& Turner, 1979; Turner et al., 1987)—even members of low-status stigmatized groups can view their identity in a positive light (Crocker, Major, \& Steele, 1998). Together, this may invite intergroup biases that diminish willingness to cooperate with other groups and compromise the performance of intergroup collaborations (Kramer, 1991; Richter et al., 2006). The challenge for intergroup leadership is to overcome this human propensity and to bridge intergroup differences in order to build cooperation and collaboration among members of two or more groups in the service of a single vision and a single sense of purpose.

There are, however, some serious obstacles to overcome in meeting this challenge. These obstacles are particularly significant when groups are central and important to how people define themselves, when groups are perceived to be in a competitive relationship, and when groups feel that there is some threat to their distinct and valued identity (Hornsey \& Hogg, 2000). It is important to note that competition and identity threat need not objectively exist-it is members' subjective perception or experience of competition and threat that drives intergroup behavior. Such perceptions can be readily provoked; indeed, the mere process of making intergroup comparisons can engender perceptions of competition and threat (Tajfel \& Turner, 1979).

The challenge of uniting different groups in pursuit of a collective vision or mission might, initially, suggest that the strong emphasis in leadership research on building a collective identity (Conger \& Kanungo, 1987; Shamir et al., 1993; von Knippenberg et al., 2004) would be especially important here-by creating or emphasizing a shared superordinate identity that included both (all) groups, leaders would reduce intergroup tensions. Indeed, in many older treatments of intergroup relations, researchers saw great value in exactly this notion of a superordinate identity (e.g., Gaertner, Mann, Murrell, \& Dovidio, 1989). More recent insights in intergroup relations as well as in social identity and leadership suggest, however, that there are at least two notable problems with this approach. The first has to do with followers' perceptions of the leader's own position in this hoped-for overarching sense of shared identity; the second has to do with several sources of resistance to groups embracing such on overarching identity.

One problem for a leader who tries to bridge intergroup divides by creating or emphasizing a shared collective identity is that it is difficult to escape being associated more closely with one group than with the other(s). Indeed, in many intergroup leadership situations, the leader is, in reality, a member of one of the groups (e.g., the school principal in our school example is a member of the teacher, not student, group), but even when this is not the case (e.g., the new director in our press example), "neutrality" in the eyes of all parties may be very difficult to achieve.

Social identity analyses of leadership emphasize the critical importance, for effective leadership, that the leader be perceived to be group prototypical-to embody and epitomize the group's identity (Hogg \& van Knippenberg, 2003). Intergroup leadership situations may challenge this perception in the extreme, in that the leader may not only be perceived as not "one of us" but may actually be perceived as "one of them"-as affiliated with the outgroup (cf. Duck \& Fielding, 2003) —and this challenge becomes bigger as group members identify more strongly with their group (Platow \& van Knippenberg, 2001). An additional complication in this respect is that as groups feel they share less in common, it may prove exceedingly difficult to create a shared sense of identity that all groups can agree upon. The prototype that the leader would strive to embody (cf. Reicher \& Hopkins, 2003) would be neither clear nor consensually shared. Illustrating this problem, Rutchick and Eccleston (2010) demonstrated that groups perceive and define 
their shared superordinate identity differently and that attempts to invoke a common superordinate identity between competitive groups backfired for outgroup leaders: outgroup leaders were perceived as missing the necessary "credentials" to impose a superordinate identity. In short, leaders would be hard put to find a solid leadership base in an overarching collective identity because their claims of representing that overarching identity would likely be contested.

Moreover, a shared collective identity implies similarity (Brewer \& Gardner, 1996; Turner et al., 1987), and groups, particularly those that are important to self-definition and viewed as in competition and facing a threat to the distinctiveness of their identity, often staunchly resist accepting an overarching identity that would suggest similarity to other groups. One reason for this is that group members can place enormous value on preserving, even promoting, the distinctiveness of their group or organizational identity (Brewer, 1991; Dutton, Dukerich, \& Harquail, 1994). As a consequence, attempts to create or emphasize an overarching collective identity can often be experienced by group members as a threat to the distinct identity of their group-a threat that invites resistance to attempts to emphasize a superordinate identity (Hewstone \& Brown, 1986; Hornsey \& Hogg, 2000).

Walking the tightrope of simultaneously acknowledging distinct group identities and emphasizing an overarching superordinate identity may alleviate this concern to some extent (Gaertner \& Dovidio, 2000). However, this is not only difficult to accomplish successfully but, unfortunately, cannot address the other problem associated with overarching collective identities: group members may subjectively experience the overarching identity as an extension of their own group identity-a process called "ingroup projection" (Mummendey \& Wenzel, 1999). This problem is especially significant in the alltoo-common situation where the groups are of unequal status or power. Such situations pose the risk that the higher-status or dominant group will project its defining attributes-its identity - onto the superordinate group in such a way as to exclude the lower-status subordinate group's identity-defining attributes (Wenzel, Mummendey, Weber, \& Waldzus, 2003). At best this produces alienation and a sense of disidentification (cf. Elsbach \& Bhattacharya, 2001) among members of the lower-status group, leading them to disengage psychologically from the situation and reduce their efforts (cf. van Knippenberg, 2000); at worst it emphasizes the intergroup divide and reduces leadership's ability to create an overarching collective identity.

This is not to deny the potential value to intergroup relations of a shared superordinate identity. If it is possible to engender a sense of shared superordinate identity, this should work to foster productive intergroup collaborations. The issue, however, is that as group memberships become more self-definitionally important to members and intergroup relationships become more precarious, attempts to establish a shared superordinate identity become less viable as a way to build productive intergroup collaborations. In our press example, for instance, if the groups could be brought to embrace a shared superordinate identity, there would be no reason not to expect this to be conducive to productive intergroup collaboration. The issue in this example, however, is that the books and journals groups perceive themselves to have important separate identities and to be differentially privileged, as well as in competition with one another, and this makes it likely that attempts to instill a sense of superordinate identity will be actively resisted.

In short, while intergroup leadership attempts to build an overarching collective identity are an obvious avenue to explore on the basis of more traditional readings of intergroup relations, state-of-the-science insights from both intergroup relations research and social identity and leadership research suggest that such attempts will have a low probability of success when groups are selfdefinitionally important-particularly when groups are viewed as in competition and facing a threat to their identity. In these circumstances such attempts may even backfire insofar as they consolidate and entrench existing intergroup distinctions. Moreover, leaders face an uphill battle in establishing leadership credentials based on being perceived as prototypical of that overarching collective identity. What, then, should intergroup leadership do? To answer this question, we need a theory of intergroup leadership. 


\section{A THEORY OF INTERGROUP LEADERSHIP}

Considering that intergroup collaborations are an arena for group identity clashes, to be effective, intergroup leadership should engage with issues of group identity. If attempts to build an overarching collective identity often cannot be the solution to this problem, what does it take for intergroup leadership to be effective? We argue that to answer this question we need to go back to the roots of the conceptual analysis of intergroup relations and reconsider the forms social identity can take (cf. Brewer \& Gardner, 1996). To capture how groups may define their identity in terms of their relationship with another group, we propose the concept of intergroup relational identity. We argue that building such an intergroup relational identity, rather than a collective identity that suggests similarity and oneness (cf. Ashforth \& Mael, 1989; Turner et al., 1987), provides a particularly powerful mechanism for effective intergroup leadership. We also identify ways in which leaders may develop such on intergroup relational identity.

\section{Intergroup Relational Identity}

First, we need to locate the new concept of intergroup relational identity in research on identity, self-conception, and intergroup relations. Traditionally, the concept of social identity-self-definition and evaluation in terms of the shared defining attributes of a group-has been positioned in contrast to personal identity-self-definition and evaluation in terms of unique personal attributes and close personal relationships (e.g., Tajfel \& Turner, 1979). It should be noted that social identity and social identification are not the same thing (Sluss \& Ashforth, 2007). The former is a cognitiveevaluative representation of self; the latter describes the cognitive process of categorizing oneself in terms of a group's attributes that transforms self-conception and generates attachment and a sense of belonging to the group (Abrams \& Hogg, 2010; Turner et al., 1987).

Recently, a more textured distinction has been drawn between different types of social identity-specifically, between collective identity/self and relational identity/self (Brewer, 2001; Brewer \& Gordner, 1996; Chen, Boucher, \& Tapias, 2006). Collective identity captures the notion of social identity around which social identity theory and self-categorization theory revolve. It is the notion of self as "we"-self-definition in terms of a shared group membership that implies similarity between, even interchangeability among, members of the group (Turner et al., 1987). Relational identity, in contrast, captures selfdefinition in terms of relationships with significant others, in which the self is understood in terms of these relationships (Brewer \& Gardner, 1996; Brickson, 2000; Lord \& Brown, 2004; Sluss \& Ashforth, 2007, 2008; Sluss, van Dick, \& Thompson, 2010).

While collective and relational identity both refer to an "extended" sense of self that includes others, the important difference between the two is that the former focuses on self-other similarity and the latter focuses on the relationship between self and other. This is not to say that similarity cannot be part of relational identity. Indeed, as self-categorization theory (Turner et al., 1987) posits, any perceptual differentiation between individuals or groups takes place against the backdrop of higher-level similarity that makes comparisons possible in the first place. Rather, the issue is that similarity is not defining of relational identity, whereas it is of collective identity. The relationship between parties is what defines relational identity, and this relationship may revolve around significant asymmetries in the distinct roles and unique attributes that the parties bring to the relationship.

Relational identities are often viewed in interpersonal terms. For example, a classic relational identity is that of a parent and child. Within the wider context of family similarity, both parties define the self primarily in terms of their relationship with the other, while the relationship, in fact, implies dissimilarity and distinctiveness. The child is dependent on the parent, the parent's responsibility is to care for the child, and child and parent are distinct and dissimilar beings, whose dissimilarities are as defining of their roles in their relationship as are their similarities. Note that relational identity is not limited to such asymmetrical relationships; it may also include relationships of equal partners, such as spouses, without implying similarity or threatening individual distinctiveness.

Relational identity is typically understood in terms of a mental representation of an individual's relationship with significant other individ- 
uals. In that sense, it may also be labeled interpersonal relational identity. We propose that to properly advance our understanding of intergroup collaboration, we should consider the possibility that self-definition can also reflect relational identities at the level of collective self-conception-intergroup relational identities that define the collective in terms of the group's relationship with one or more other groups. While this is an option that has not really been considered in research on social identity and self-construal, it actually fits well with everyday observations. Consider, for instance, how professional groups are often defined precisely by their relationships with other groups, such as teachers through their relationship with pupils and doctors through their relationship with patients-an observation that easily extends to formal groupings within a specific organization, such as the group of teachers within a particular school vis-à-vis the group of pupils within the school.

Examples such as the teacher-pupil relationship are powerful illustrations of the concept of intergroup relational identity; indeed, this is why we have used this example. One might argue, however, that teachers-pupils is such a strong intergroup relational identity (i.e., no teachers without pupils, no pupils without teachers) that it does not present the same intergroup leadership challenge as do the other organizational examples we described above (i.e., a hospital, a press). But perhaps this disparity is more apparent than real. Schools do indeed become dysfunctional when teachers as a group and students as a group view each other as distinct entities that are in conflict, and it can be difficult for school heads to provide leadership. (In our example the principal needed to provide leadership in the context of a specific activity-a canned-food drive.)

An example where it is perhaps easier to see the scope for intergroup relational identity that comes closer to the examples of intergroup leadership challenges we raised earlier is a group of doctors and a group of nurses within a hospital. Research shows that when these groups are in conflict, the core business of the organization can be seriously compromised, and the hospital's leadership needs to refrome identities in ways that bear a close resemblance to our characterization of an intergroup relational identity (e.g., Oaker \& Brown, 1986). Our press example, in which the books and journals divisions are in opposition, is another example of an intergroup leadership challenge as faced by many organizations.

Our new concept of intergroup relational identity can best be positioned relative to personal, relational, and collective identity in a matrix formed by two dimensions: focus of identity and focus of comparison (see Figure 1). Personal identity is the individual self defined as different and distinct from a specific individual, collective identity is the self defined in group terms as different and distinct from a specific outgroup, interpersonal relational identity is the individual self defined in terms of its relationship with a specific individual, and intergroup relational identity is the self defined in terms of the relationship between one's own group and a specific outgroup. It is important to note that identities are cognitive representations in the mind of the individual that to varying degrees reflect or generate a corresponding reality, and people are unlikely to be able to sustain an identity for long if there is little correspondence with reality.

FIGURE 1

Forms of Identity As a Function of Focus of Identity and Focus of Comparison

Focus of identity

Focus of comparison Individual Group

\begin{tabular}{|c|c|c|}
\cline { 2 - 3 } Differentiation & Personal identity & Collective identity \\
\cline { 2 - 3 } Relationship & Interpersonal relational identity & Intergroup relational identity \\
\hline
\end{tabular}


In intergroup collaboration, an intergroup relational identity would entail a sense of identity that included or was even defined by the collaborative relationship existing with the other group; collaboration would be a key component of the internalized self-defining normative attributes of the specific intergroup relational identity (from a social identity perspective, norms have the greatest influence over people's perceptions and behavior if they are an integral part of social identity; even when social identity includes more than group norms, group norms are an integral part of identity [Hogg \& Smith, 2007; Turner, 1991]). Reflecting back to our press example, an intergroup relational identity might exist if the members of the books and journals divisions defined themselves as distinct and valued parts of the press entwined in an essential mutually collaborative relationship.

Such a sense of identity is important in overcoming identity clashes that are often associated with intergroup relations. Of critical importance, however, and in contrast to an overarching collective identity, such an intergroup relational identity would imply an extended sense of self (i.e., including the relationship with the other group), without privileging perceptions of similarity to the other group (cf. Brickson's [2000] argument regarding the interpersonal advantages of interpersonal relational identity over collective identity). Indeed, relational identity may, in fact, be defined in terms of groups' distinctive and unique roles in the collaborative relationship. For intergroup leadership, we propose that aiming for the establishment of an intergroup relational identity therefore has important advantages over striving for the creation of a shared collective identity in intergroup collaborations.

First, the intergroup similarity implied by an overarching collective identity tends to invite resistance fueled by a desire to maintain group distinctiveness. An intergroup relational identity, in contrast, revolves around the collaborative relationship, does not imply intergroup similarity, and allows groups to maintain their distinctiveness. It satisfies Berg's (2005) evocative injunction, aimed at those who wish to resolve intergroup tensions, to "let people have their groups." Attempts to build on intergroup relational identity thus do not invite the kind of resistance that attempts to instill a sense of overarching collective identity do, nor do they invite the problems associated with ingroup projection, while they do allow for the establishment of an extended sense of self that includes the collaboration partner.

Second, attempts to build an overarching collective identity inevitably present intergroup leadership with the group prototypicality problem: it is difficult to establish oneself as representing the shared collective identity and all too easy to be seen as representing one of the groups. An intergroup relational identity would not pose the same problem since there would be no unified group prototype as a referent for leadership perceptions. If anything, intergroup leadership would be expected to embody the intergroup relationship, which is a much more realistic objective to accomplish (an issue we address in the following section). Moreover, to the extent that a leader would be associated with one of the collaboration partners, this would be less problematic since the intergroup relational identity would lead group members to perceive the other group as a valued partner in the relationship.

In sum, given that intergroup collaborations typically, if not inevitably, are associated with potentially disruptive social identity processes, the intergroup leadership challenge at its core requires speaking to group members' social identity. The advantages to leaders of focusing on intergroup relational identity in this respect are many-particularly where there is a deep intergroup divide. It buys trust in the leader because it avoids identity threat (concern over erosion of group distinctiveness) and is instead transparent and honest in acknowledging real intergroup differences. Furthermore, by not focusing on imposing an overarching collective identity, it sidesteps ingroup projection issues and issues revolving around the extent to which a leader is perceived to be "one of us" or "one of them." At the same time, it does allow leadership to create an extended sense of identity that helps prevent intergroup identity clashes. Intergroup leadership is effective if two or more distinct formal groups within an organization collaborate naturally and harmoniously to achieve joint intergroup goals set by the leader-the development of an intergroup relational identity is, we argue, key to intergroup leadership effectiveness. 
Proposition 1: Intergroup leadership is more effective if it is aimed at creating an intergroup relational identity rather than (a) a superordinate collective identity or (b) an identity that does not include both/all groups.

As we foreshadowed above, Proposition 1 does not deny the potential value of a shared superordinate identity. Rather, it recognizes that attempts to establish such an identity become increasingly problematic when intergroup division becomes stronger (i.e., there is greater subjective intergroup competition and identity threat-greater concern about erosion of group distinctiveness and valued identity), when groups are of unequal status and power, and when group members identify more strongly with their group-not because superordinate identity, if established, would not motivate intergroup collaboration but because of the fact that attempts to establish superordinate identity would be unlikely to be successful. Accordingly, we propose that the benefits of intergroup leadership focused on the creation of an intergroup relational identity, resting on recognition of groups' equal worth within the collaborative relationship, become more evident when group identities are more deep seated and intergroup relations are more polarized and emotionally charged.

Proposition 2: Intergroup leadership focused on intergroup relational identity, as compared with a superordinate collective identity or an identity that does not include both (all) groups, becomes a more effective leadership strategy when (a) group members identify more strongly with their group, (b) there is greater (subjective) identity threat and competition between groups, and (c) groups are of more unequal status and power.

\section{Leadership to Build Intergroup Relational Identity}

Our analysis so far has proposed the new concept of intergroup relational identity and argued that intergroup leadership is more effective when it builds such on identity connecting groups in intergroup collaboration. This begs the theoretically and practically important question of how leaders may accomplish this. Because intergroup leadership has not really been on the agenda of leadership research and because intergroup relational identity is a new concept, there are no ready answers in the literature. What has been established, however, is that on important leadership function is giving meaning (i.e., sensemaking; Weick, 1993; see also Ospina \& Foldy, 2010), which includes shaping followers' understanding of group identity (Reicher \& Hopkins, 2003). Indeed, Reicher and Hopkins suggest that highly successful leaders can often be viewed as "entrepreneurs of identity," who are in the business of persuading group members of a reading of the group's identity that positions the leader as highly prototypical-an individual whose vision, mission, or objectives are tightly consistent with the group's identity. That is, leadership may not only build social identification with the group or organization (cf. van Knippenberg et al., 2004); it may also shape group members' understanding of what the group's identity is.

The current question, thus, is how leaders can be successful entrepreneurs of intergroup relational identity. As is more often the case for effective leadership (cf. Conger \& Kanungo, 1987; van Ginkel \& van Knippenberg, in press), we propose that the answer to this question lies in the combination of leadership rhetoric and leader actions that presents the leader as a role model to match that rhetoric-in this case leadership rhetoric that emphasizes intergroup relational identity and boundary-spanning leadership behavior that embodies and exemplifies the collaborative intergroup relationship.

Rhetoric and identity entrepreneurship. Social identity analyses of leadership and analyses of charismatic-transformational leadership alike have noted that leaders may shape follower conceptions of their shared collective identity through rhetoric, invoking and describing the collective identity in ways that suggest specific attributes of the shared identity that are in line with the leader's vision (e.g., Hogg \& Reid, 2006; Reicher \& Hopkins, 2003; Seyranian \& Bligh, 2008; Shamir et al., 1993). Intergroup leadership may likewise-through speeches, visionary communications, and so forth-give meaning to intergroup collaboration in ways that focus on the identity implications of intergroup collaboration. While this rhetoric may also include more instrumental considerations regarding the 
mutual benefits of intergroup cooperation and collaboration, it should clearly emphasize the linkage between intergroup collaboration and valued aspects of the group's identity (i.e., how the intergroup collaboration is essential to achieving outcomes that are deeply valued by the group, such as radically innovative products, the highest-quality patient care, etc.). Moreover, it should explain how the whole is significantly greater than the parts and depends on the distinctive and valued qualities that each group brings to the table; it should identify the intergroup collaborative relationship as a unique way to arrive at outcomes closely associated with group identity but not threatening to perceived group distinctiveness and value. By championing the collaborative relationship rather than the collective identity, the leader may also position him or herself to be perceived as representing that relationship-to be prototypical of the intergroup relational identitythus building a leadership base from the understanding of group identity that he or she has brought into being (cf. Reicher \& Hopkins, 2003).

This process of constructing on intergroup relational identity would not, indeed could not, be instantaneous; rather, it would unfold over time. Initially, the groups may view their relationship to one another as largely pragmatic and instrumental-a surface behavioral collaboration that may have a beneficial payoff but does not actually define their identity. Such a conception in terms of instrumental value would be on effective foundation for leader identity rhetoric, lending credibility to leaders' claims regarding the favorable identity implications of the intergroup collaborative relationship. In contrast, intergroup identity rhetoric that cannot connect to any preexisting conception of the value of the intergroup relationship would undermine leadership credibility and legitimacy.

Just as social exchange (i.e., instrumental) relationships may be precursors to identity relationships (Sluss, Klimchak, \& Holmes, 2008), an instrumental understanding of the intergroup collaboration may be transformed into on understanding in identity terms if the leadership rhetoric is credible and makes logical sense in linking instrumental considerations to identity, and if it is delivered consistently and repeatedly over time and modality. Through intergroup leadership rhetoric that provides a shift from a more instrumental intergroup relationship to an intergroup relationship that is part of group identity, members will, over time, come to view the nature of the relationship as identity defining, and they will be more likely to internalize it, through the process of self-categorization, as part of an intergroup relational identity.

Proposition 3: Leader rhetoric that defines group identity in terms of a complementary intergroup collaborative relationship is positively related (a) to the development of intergroup relational identity and, thus, (b) to intergroup leadership effectiveness.

Spanning intergroup boundaries. Leaders' identity-shaping rhetoric is important, probably critically so, but needs to be backed up with behavior. If leader rhetoric is not matched by leader action, it is less likely to be effective in building intergroup relational identity and, thus, less likely to be effective in producing intergroup collaboration. Leaders need to act in ways that embody the rhetoric. The notion of boundary spanning (e.g., Callister \& Wall, 2001) is important here, both when it comes to building an intergroup relational identity and in terms of leaders' ability to position themselves as prototypical of that identity.

Boundary spanning is defined as a situation in which someone has one or more relationships that bridge two otherwise unconnected social networks (e.g., Oh, Chung, \& Labianca, 2004). Boundary spanners are group members who have strong links and significant interactions with outgroup members and, thus, are potentially able to defuse intergroup conflicts and facilitate smooth intergroup interactions. In organizational contexts, boundary spanners are often group leaders, since they have to speak for and manage what happens within and between groups; they must lead two or more groups working toward a shared goal, regardless of any animosity that might exist between the groups. In our hospital example, to demonstrate boundary-spanning leadership, the director (usually a doctor) would need to have strong and genuine relationships with both the group of doctors and the group of nurses. Boundary spanning can thus contribute to successful intergroup leadership (Ernst \& Yip, 2009). Richter and colleagues (2006) found, for instance, that leader boundary spanning was associated with lower conflict be- 
tween groups and higher intergroup productivity.

We propose that the importance of boundary spanning to intergroup leadership lies foremost in the role boundary spanning may play in creating and maintaining an intergroup relational identity. Boundary-spanning leadership in a sense embodies the intergroup relation. However, in itself, boundary-spanning leadership will be insufficient to establish intergroup relational identity, but what it should do is create a role model (cf. Conger \& Kanungo, 1987; van Ginkel \& van Knippenberg, in press) that lends credibility to leaders' rhetoric emphasizing the intergroup relationship as an aspect of group identity. Boundary spanning acts as a moderator of the impact of rhetoric on intergroup relational identity. By being seen as in line with the rhetoric promoting intergroup relational identity, boundary spanning may strengthen the impact of leaders' attempts to link the collaborative intergroup relationship to group members' understanding of group identity. Moreover, a leader's role as boundary spanner may consolidate group member perceptions that the leader is indeed prototypical of the relational identity, thus amplifying the leader's basis for having influence in the intergroup collaboration.

\section{Proposition 4: Boundary-spanning leadership acts as a moderator, en- hancing the impact of leader rhetoric targeted at establishing intergroup re- lational identity and, thus, the impact of leader rhetoric on intergroup lead- ership effectiveness.}

Proposition 4 implies that effective intergroup leadership is a function of the interplay of leader rhetoric and leader boundary spanning. Neither leader rhetoric nor boundary spanning should be viewed as one-off events. Rather, they unfold over time, with one gaining in influence as a function of the other. There is an important temporal dynamic to intergroup leadership, just as there is in many other processes in organizational behavior (Mohammed, Hamilton, \& Lim, 2009). The influence of boundary-spanning leadership and the influence of intergroup identity rhetoric are mutually reinforcing. Boundaryspanning leadership adds to the credibility of leadership rhetoric, and leadership rhetoric shapes understanding of what boundary-span- ning leadership exemplifies and therefore what its influence is.

Furthermore, as the interplay of leader rhetoric and leader boundary spanning builds intergroup relational identity, the emergence of a sense of intergroup relational identity, in turn, validates and facilitates the effectiveness of the leader's rhetoric and boundary-spanning behavior. This intergroup leadership dynamic mirrors what happens in intragroup leadership situations-leadership that builds a shared social identity also creates more fertile ground for subsequent leadership targeted at this shared social identity (van Knippenberg \& Hogg, 2003), and, more generally, the effectiveness of group leadership is contingent on earlier leadership actions (Hackman \& Wageman, 2005). In studying intergroup leadership, as well as in developing intergroup leadership proctices, these temporal dynamics deserve close attention.

In reference to Proposition 4, it is also important to note that boundary-spanning leadership should be understood as building high-quality interpersonal relationships that cross group boundaries and not just as intergroup contact per se. Just as interpersonal relational identity evolves in the context of an ongoing highquality interpersonal relationship and does not follow automatically from mere interpersonal contact (Brewer \& Gardner, 1996), boundaryspanning leadership should set the stage for intergroup relational identity by building highquality interpersonal relationships that may function as a role model for intergroup collaborative relations.

A final observation in reference to Propositions 3 and 4 is that such leadership may be supported by other leader actions (e.g., developing certain group "rituals" to underscore identity rhetoric) that may add to the effectiveness of intergroup leadership. Such actions in and of themselves would not so much build intergroup relational identity but, rather, would support leadership rhetoric and boundary-spanning's influence in this respect. We propose that the leadership highlighted in Propositions 3 and 4 lies at the core of successful intergroup leadership.

A boundary-spanning leadership coalition. Boundary spanning may also be particularly important in tackling one of the key challenges of intergroup leadership: being an ingroup leader for one of the groups makes one an outgroup 
leader for the other group(s). This problem may, however, be alleviated if intergroup leadership is provided by a collaborative partnership of leaders of the different groups that is formed to shape the intergroup collaborative efforts-a boundary-spanning leadership coalition.

Boundary spanning and intergroup relational identity rhetoric help position group leaders in the relationship between groups rather than solely within one of the groups and therefore attenuates potentially negative effects of being perceived as outgroup leaders. Even so, leading the outgroup may still be an uphill battle. We propose that an important way in which intergroup leadership can win this battle to build an intergroup relational identity is through the formation of a boundary-spanning leadership coalition that renders intergroup leadership a joint effort of all group leaders involved, rather than an enterprise championed by a single individual.

In situations where the leaders of the different groups involved hold the primary responsibility for making the intergroup collaboration a success (as will most often be the case), each of these leaders faces the challenge of being able to have an impact on the members of the other group(s) only to a modest degree. Indeed, particularly when it comes to defining or redefining group identity, outgroup leaders seem especially poorly positioned owing to questions concerning their legitimacy to speak to group identity (e.g., Rutchick \& Eccleston, 2010). Thus, while it is not impossible for intergroup leadership to be grounded solely or primarily in one leader, a more robust scenario is one in which the leaders of the different groups involved share the leadership challenge. While leadership targeted at engendering intergroup relational identity may be particularly effective in building intergroup collaborative performance, this leadership will be more effective if it is delivered to the members of each group by a leader who is perceived as their own leader. Reflecting back on our press example, the new director might be a more effective intergroup leader if he or she were to form a leadership circle or coalition that also included the leaders of the books and journals divisions.

Our analysis thus far has revolved around what intergroup leadership should aim for, but because the focus has been on the efforts of $a$ single individual, the problem of leading the outgroup has always potentially been present. Boundary-spanning leadership coalitions to a great extent disarm this problem because leader-leader relationships ensure that intergroup leadership becomes a shared effort, and a consistent message is delivered across group boundaries by a leader perceived to be on ingroup leader. The key point here is that intergroup leadership is more effective as shared action of all group leaders involved than as an individual leader's action.

An intergroup leadership coalition would make it possible for the primary influence in building intergroup relational identity for any particular group to flow from the ingroup leader. Moreover, the ingroup leader's boundaryspanning relationships would make outgroup leaders appear favorably linked to and sympathetic toward the ingroup and would therefore lend credibility to outgroup leaders addressing group members across group boundaries. In this sense, intergroup leader-leader relations may be more important and impactful for intergroup leadership than intergroup leader-member relationships.

Importantly, for such boundary-spanning coalitions to be optimally effective, leaders should primarily understand their relationship as lying in the intergroup and not the interpersonal domain (cf. Hewstone, 1996); approaching one another in a depersonalized manner as representatives of each leader's respective group, rather than on an interpersonal or personalized basis, is what sets the stage for a shared understanding of the intergroup collaboration. Leaders should see their task as being to approach each other against the backdrop of intergroup relational identity, not an attempt to build interpersonal relational identity. It is by representing their groups in their leader-leader relationships that they build intergroup relational identity.

Some positive personalized regard (cf. Sluss \& Ashforth, 2007) among leaders will facilitate the establishment of a boundary-spanning leadership coalition, but too close a network of personal relationships among members of the coalition will seriously compromise the coalition's leadership potential. Followers might begin to view the coalition as an autonomous entity- $a$ cozy friendship clique-and, thus, distrust the coalition's motives and commitment to their respective groups and hence their legitimacy to lead the overarching group as a whole. 
Establishing a boundary-spanning leadership coalition is not easy. There are many obstacles to cooperation within a boundary-spanning leadership coalition (e.g., Wageman, Nunes, Burruss, \& Hackman, 2008), just as there are many obstacles to establishing effective intergroup collaborations more generally. Importantly, however, a focus on establishing intergroup relational identity should render establishing a boundary-spanning leadership coalition more feasible. The emphasis on intergroup relational identity would recognize the different groups and their leaders as distinct and valued partners and would thus be less associated with the problems that typically burden intergroup collaborations (including intergroup leadership coalitions; Wageman et al., 2008). This emphasis on valued partnership would help create a climate of mutual trust, respect, and liking, in which the boundaryspanning coalition may be built. Through such a boundary-spanning leadership coalition, leaders may jointly exemplify precisely the intergroup relational identity they are striving to construct.

Another reason this strategy would be effective is that it would indirectly improve intergroup attitudes through a process called "extended contact" (Davies, Tropp, Aron, Pettigrew, \& Wright, 2011; Wright, Aron, McLaughlin-Volpe, \& Ropp, 1997; Wright, Aron, \& Tropp, 2002). When people view a trusted, liked, or prototypical ingroup member having prolonged pleasant interactions with a prototypical outgroup member, their attitude toward the outgroup as a whole can improve-intergroup anxiety, dislike, distrust, threat, and so forth can diminish. This significantly helps realize intergroup relational identity and makes effective intergroup leadership easier.

\begin{abstract}
Proposition 5: Intergroup leadership targeted at engendering intergroup relational identity is more effective when it is undertaken by a leadership coalition that unites leaders of both (all) groups than when one or more group leaders do not take part in such a coalition.
\end{abstract}

The processes coptured by Proposition 5 will become increasingly important as intergroup status and power differences grow larger. As we noted previously, intergroup collaborations may involve equal partners, but as a result of differ- ences in size, access to valued resources, value placed within the organization on the functions fulfilled by the different groups, and so forth, in many cases one group will be of higher status or more powerful than the other (e.g., doctors and teachers in the hospital and school scenarios, respectively). In many such instances, these status and power differentials ensure that the intergroup collaboration is dominated by the higher-status, higher-power partner (cf. van Knippenberg, van Knippenberg, Monden, \& de Lima, 2002). This may invite all the problems associated with ingroup projection processes discussed earlier, at the expense of the quality of the intergroup collaboration.

A boundary-spanning leadership coalition characterized by high-quality relationships between the leaders of the groups involved may help prevent such negative effects of power differentials (cf. Wageman \& Hackman, 2010), especially when combined with leader rhetoric targeted at building intergroup relational identity. This arrangement may be particularly effective because it recognizes the lower-status, less powerful group (e.g., nurses and students) as a valued, and in many ways equal, partner, particularly through the recognition of its unique contribution to a valued aspect of group identity. That is, even when groups do not have equal status and power within the organizational context, they may treat each other as equal partners within the intergroup collaboration, and a focus on intergroup relational identity would include on emphasis on this equal and valued partnership.

\section{Fresh Faces, Ingroup Leaders, and Outgroup Leaders}

Our analysis so far applies primarily to situations in which intergroup leadership is provided by leaders who are members of the groups involved in the intergroup collaboration. This need not necessarily be the case. In intergroup collaboration the organization within which the groups are nested may also set up a leadership structure that deliberately places at the head of the intergroup collaborative efforts a leader who is not a member of any of the groups involved (e.g., an external hire to lead a joint venture; a CEO brought in from outside rather than promoted from a position tied to one of the organizational departments, units, or divisions). An obvious question from the current perspective 
concerns how effective such unaffiliated leaders are in establishing a sense of intergroup relational identity and fostering a perception that they are prototypical of that identity. Would it be wise to appoint an external leader for intergroup collaborative efforts, in order to manage the intergroup relationship through, to put it in negotiation terms, "third-party mediation" (cf. Thompson, 2009)?

Initially, appointing on unaffiliated individual from outside would seem a sensible solution to the intergroup leadership problem. As outlined above, one of the key challenges of intergroup leadership is overcoming obstacles associated with being viewed as an outgroup leader. If the leader is genuinely viewed as a member of neither (or any) constituent group, this may appear to be the ideal scenario for intergroup leadership. The leader would presumably be seen as unbiased toward either (or any) group and therefore as constructing an intergroup relational identity in a disinterested and impartial manner that captures the mutually beneficial relationship of the groups as a defining attribute of each group and of the overarching context (e.g., organization). The leadership knack here would be to remain aloof from group loyalties and conflicts within the organization-to avoid being seen to have favorites from one group or the other, and to be careful in adopting a language not privileging one group.

But not being associated with the outgroup comes at a price-not being part of the ingroup (cf. van Knippenberg \& Hogg's [2003] discussion of interim leadership). As noted above, especially when it comes to shaping group identity, ingroup credentials seem critical to the leader's legitimacy-what unaffiliated leaders would gain on the one hand they would lose on the other, and it is not self-evident that the loss would not be more impactful than the gain. Indeed, Reicher and Hopkins's (2003) analysis would seem to suggest that leaders gain their legitimacy and influence as entrepreneurs of identity through a complex interplay between being seen as group prototypical and being perceived to advocate $a$ construction of identity that is aligned with, even when deviating from, followers' sense of identity; leaders can change followers' sense of identity only by maintaining a sense of continuity and consistency of identity (van Knippenberg, van Knippenberg, \& Bobbio, 2008). Ingroup leaders are much better posi- tioned to do this than unaffiliated leaders, who remain outgroup leaders of sorts. Given the critical role of intergroup relational identity in effective intergroup leadership, ingroup credentials thus seem important in effective intergroup leadership.

The notion of a boundary-spanning leadership coalition may be important here, because the intergroup effectiveness of unaffiliated leaders in particular may benefit from such a coalition with affiliated leaders (i.e., leaders that are ingroup members of one of the groups in the collaborative relationship)_for example, our new press director may find this particularly advantageous since he or she has come into the organization from outside and is therefore unaffiliated with any of the partners in the intergroup collaboration. In the absence of such a coalition, affiliated leaders have two important advantages: (1) they can speak to their own group as an ingroup leader, and (2) in building a relationship with the other group(s), their actions embody the intergroup relationship. Even as the initiative of a single individual, an affiliated leader thus has some basis to advocate and exemplify intergroup relational identity. In contrast, by being unaffiliated with any of the groups, unaffiliated leaders are less well positioned to exemplify the intergroup collaborative relationship and lack ingroup credentials in speaking to at least one of the groups. Therefore, although affiliated leaders benefit from an intergroup leadership coalition to address the problem of lower credibility with the outgroup, unaffiliated leaders' intergroup effectiveness benefits particularly decisively from such a coalition; this coalition provides a platform that allows the leadership group's actions critical to the building of intergroup relational identity to flow through leaders who are viewed as ingroup by the group members involved.
Proposition 6: A boundary-spanning leadership coalition contributes more to the effectiveness of an unaffiliated leader than to the effectiveness of an affiliated leader in leading intergroup collaborative performance.

\section{Transference of Intergroup Relational Identity}

Our analysis so far has proposed that effective intergroup leadership revolves around the 
establishment of intergroup relational identity through two interacting leadership processes: identity rhetoric and boundary spanning. These processes are important in and of themselves, but they also mutually enhance each other's influence. Boundary spanning allows a leader's rhetoric to extend beyond the boundaries of the ingroup; it provides an intergroup audience rather than only an intragroup audience and, thus, increases the reach of the leader's identity rhetoric. At the same time, rhetoric focused on building intergroup relational identity gains credibility and effectiveness when it is exemplified by the leader's boundary-spanning activities and the leader's own relationships that cross group boundaries.

Clearly, this is not a straightforward or simple process-it takes time and energy. For intergroup collaborations that endure for some time, such on investment in identity management and relationship building seems warranted, given the problems associated with intergroup relations. But the investment required begs the question of whether and how similar strategies may be used in contexts of more numerous and perhaps also shorter-lived intergroup collaborations. As groups enter into new or more shortlived intergroup collaborations, might identity rhetoric and boundary spanning still provide the key to effective intergroup leadership? We propose that they may and that a process termed transference is key. This term has its roots in psychoanalytic theory and can also be understood to have implications for emotional dynamics in organizational contexts (e.g., Alderfer, 2010), but we use it here purely in its socialcognitive sense (Andersen \& Chen, 2002).

To introduce and illustrate our concept of intergroup relational identity, we used the example of how the professional identity of teachers is shaped by their relationship with pupils (i.e., pupils clearly are not teachers, but teacher identity is defined through the relationship with pupils). Extending this example, we may also observe that teacher identity is not defined by the relationship with one specific pupil or one specific class of pupils but, rather, by a more generalized relationship with different pupils over time. We believe that the notion of transference, from research on interpersonal relational identity (Andersen \& Chen, 2002; cf. Ritter \& Lord, 2007), is important here.
Transference refers to a process by which the cognitive representation of one's well-established relationship with one partner (cf. relational identity) may be projected onto a new relationship with a partner who is felt to resemble, in the sense of having a "fomily resemblance" to (e.g., Wittgenstein, 1953), the partner from the well-established relationship. In short, if you meet someone who reminds you of your best friend, you may project qualities of your relationship with your best friend onto that emerging relationship. In this way, the process of relational identity transference may help establish a relational identity encompassing a new relationship.

Transference can also be understood from a social categorization perspective as applying to different members of the same group-categorization of self and others as members of the same group depersonalizes perception so that self and others are all viewed in terms of the relevant group prototype (Turner et al., 1987). Thus, one's relationship with one group member is considered "identical" to (transferable to) one's relationship with any and all other members of the same group (Abrams \& Hogg, 2010; Hogg, 2006). Going back to our earlier example of doctors and nurses, once categorized as a doctor or nurse, the self and others are perceived in terms of the relevont group membership and less so in terms of distinct, individuating characteristics. This process underscores perceived similarity among members of a group and therefore sets the stage for relationship transference to other members of the same group. In our example it helps doctors quickly establish a relationship with new nurses. Because they are nurses, new nurses easily fit into doctors' sense of identity that includes relationships with nurses in general, even when this sense of identity originally revolved around other specific nurses.

Of most relevance to the current analysis is the likelihood that this process extends to intergroup transference-an intergroup relational identity may be transferred from one intergroup relationship to another when the cognitive representation of a well-established intergroup collaboration is projected onto the new intergroup relationship it is felt to resemble. Keeping with the doctor-nurse example, nurses might transfer their cognitive representation of their relationship with doctors to hospital administrators, 
specialists, team coaches, and the like if they feel the latter intergroup relationships resemble the former (cf. Sluss et al.'s [2010] discussion of generalized role expectations and role identity; see also Sluss \& Ashforth, 2007).

Turning to the issue of intergroup leadership, we propose that intergroup leadership may stimulate the process of intergroup relational identity transference. If leadership is able to establish transference from an intergroup relational identity based on a well-established intergroup collaboration to a new collaboration partner, it will have an advantage in establishing and effectively leading new intergroup collaborations, in the sense that it can more swiftly and with less effort establish a perception of the intergroup collaboration as not only consistent with but part of group identity.

Indeed, what this notion of transference suggests is that intergroup leadership may more quickly establish a sense of identity incorporating a new intergroup relationship if leader rhetoric is targeted at transference of older, wellestablished relationships to this new collaboration. By highlighting how the new relationship resembles valued earlier and ongoing relationships, leadership may extend a group's existing sense of intergroup relational identity to include the new intergroup relationships. In a sense, the older relationships are role models for the new relationship, and leader rhetoric that portrays them in this way may invite transference of relational identity to this new relationship. Note that similarity, to a certain extent, is in the eye of the beholder, and it is part of leaders' role as sensemakers to emphasize those aspects of the intergroup collaborations in their rhetoric that would point to these similarities.

\section{Proposition 7: As groups enter new in- tergroup collaborations, leadership rhetoric that stimulates transference of well-established intergroup rela- tional identity to new intergroup collab- orations results in greater and swifter intergroup leadership effectiveness.}

Proposition 7 further develops the temporal dynamic in our analysis. Initially, in the absence of a well-developed sense of intergroup relational identity, intergroup leadership requires the interplay of identity rhetoric and boundary spanning to build intergroup rela- tional identity. Once a group has established a clear sense of intergroup relational identity, however, intergroup leadership may build on this when entering new intergroup collaborations by engendering a process of transference of relational identity. In doing so intergroup leadership may, over time, even build a more generalized intergroup relational identity-an identity that is less bound to specific intergroup collaborations and more generally portrays the group as one that builds valued relationships with other groups. As a result, as the group develops a more general sense of identity to include collaborative relationships with other groups, it may incorporate with increasing ease new intergroup collaborations into the group's sense of identity.

The process of transference may provide a basis for effective intergroup collaboration as the group enters a new relationship, but this is not to say that the understanding of the new intergroup collaboration will remain limited to this transferred representation of an earlier relationship. As groups build experience with each other in the course of their intergroup collaborative efforts, group members may develop and refine their understanding of the intergroup relational identity to gradually become more specific to the new intergroup relationship and not limited to the transferred understanding of the older relationship.

\section{CONCLUSIONS AND DIRECTIONS FOR FUTURE RESEARCH}

In this article we argued that stimulation of effective intergroup collaborations is an important leadership function and that development of a sense of intergroup relational identity is key to successful intergroup leadership of formal organizational groups. This is particularly the case when such groups are self-definitionally important, the groups have a relatively competitive orientation toward one another, members are sensitive to threats to their own group's identity, and intergroup status and power differences are larger. Following from this, we identified a number of actions leaders should take to build such an intergroup relational identity and, thus, sponsor effective intergroup performance: leader rhetoric championing the intergroup collaboration as a valued aspect of group identity, boundary spanning to exemplify the intergroup 
relationship, formation of a boundary-spanning leadership coalition, and leader rhetoric to stimulate transference of well-established intergroup relational identity to new collaboration partners.

The consideration of intergroup leadership is new to the leadership field-both to leadership research and to the practice of leadership training and development (Pittinsky, 2009)—and the concept of intergroup relational identity is unique to the current analysis. Not surprisingly, even though our analysis has strong roots in identity and intergroup relations research, our propositions remain to be tested empirically in a systematic way. An important task in further developing the analysis of intergroup leadership therefore lies in conducting such empirical tests. Obviously, we would prioritize testing hypotheses that follow directly from our propositions.

Although operationalization of complex constructs is always a challenge (cf. Mathieu, Cobb, Marks, Zaccaro, \& Marsh, 2004), the measurement (and manipulation) of the key concepts in our analysis can build on the firm ground of prior research. Measurement of intergroup relational identity can build on earlier work operationalizing other aspects of social self-definition: personal identity, interpersonal relational identity, and collective identity, such as found in the work of Mael and Ashforth (1992), Singelis (1994), and Johnson, Selenta, and Lord (2006). In addition, there are hundreds of studies in the general social identity literature in which researchers have measured and manipulated social identity in a very wide variety of ways that cater to the specifics of the group and research context (for an overview see Abrams \& Hogg, 2010).

Likewise, analyses, measures, and manipulations of leader collective identity rhetoric (e.g., Reicher \& Hopkins, 2003; Seyranian \& Bligh, 2008) and leaders' appeal to collective identity (e.g., Shamir, Zakay, Breinin, \& Popper, 1998) offer concrete foundations for the effective operationalization of these aspects of our analysis and for the development of operationalizations of their counterparts in leadership targeted at intergroup relational identity. Prior research also offers a firm foundation for the operationalization of boundary-spanning leadership and intergroup performance (Richter et al., 2006) as indicators of intergroup leadership effectiveness.
With these basic building blocks in place, research can readily test predictions about the greater intergroup effectiveness of leadership targeting intergroup relational identity (i.e., as opposed to collective superordinate identity) and the mediating role of intergroup relational identity in this process. It can also confirm the proposed interactive and mutually reinforcing effects of leader rhetoric targeting relational identity and leader boundary spanning, the added value of a boundary-spanning leadership coalition in this process, and so forth. Importantly, because there is a clear temporal dynamic to our analysis, such research would ideally be longitudinal (cf. Ployhart \& Vandenberg, 2010) in mapping the development of intergroup relational identity and intergroup performance as a function of intergroup leadership over time. Inevitably, this would be a multistudy enterprise that would include measurement development; however, the present analysis provides a clear roadmap for such an endeavor in the set of propositions we advanced.

In this article we also discussed transference, intentionally focusing on transference as a social-cognitive process (e.g., Andersen \& Chen, 2002) in order to tie it directly to social categorization and social identity mechanisms. However, transference is also a psychodynamic construct that has implications for unconscious emotional dynamics in group and organizational contexts (e.g., Alderfer, 2010). This latter perspective on transference broadly resonates with recent research in social psychology that focuses on group-based emotions (e.g., Kessler \& Hollbach, 2005; Mackie, Maitner, \& Smith, 2009). The overarching idea here is that people generally have positive emotions about groups they belong to and negative emotions about outgroups. The implication for transference in intergroup leadership, which remains to be explored, is that transference of intergroup relational identity to a new intergroup collaboration could be a particularly powerful driver of intergroup effectiveness because it would also imply the transference of the positive emotions associated with the older collaboration, and these emotions, in turn, may at a subconscious level fuel harmonious intergroup collaboration.

Our focus in this article has been on intergroup leadership. However, the concept of intergroup relational identity is a unique contribution of the proposed theory that has potentially 
for-reaching implications outside the specific domain of leadership-for instance, in the study of intergroup relations in organizations more generally (cf. van Knippenberg, 2003). Our analysis suggests that intergroup relational identity may be widely conducive to effective intergroup performance, and it thus raises the question of what other influences, aside from leadership, there may be on the development of such self-definition.

Relations between groups may, for example, differ in how readily or easily members can view the intergroup relationship as central to their own group. In our teachers and pupils example, one group has little meaning without the other, and, accordingly, we would expect intergroup relational identity to develop with relative ease. As intergroup relations become less obviously group defining, intergroup relational identity would be less likely to develop spontaneously or quickly; more situational influence would be required (e.g., leadership).

Further development of our analysis may also focus on the possibility that intergroup relational identity may set the stage for the later development of a shared superordinate identity. Sluss and Ashforth (2008) suggest that the development of interpersonal relational identity may be the stepping-stone for the development of collective identity. In a similar vein, it is possible that intergroup relational identity may, under the right conditions, be an important step toward establishing shared superordinate identity-for instance, in the case of mergers and acquisitions, where the envisioned end state is to subsume premerger identities into a unifying postmerger identity.

Research on self-definition also suggests that there are individual and cultural differences in the extent to which people are prone to see the self in individualizing or relational terms (Brickson, 2000; Heine, 2010; Markus \& Kitayama, 1991). Such differences may also affect the effectiveness of leadership focused on intergroup relational identity. On the one hand, it may be easier to establish on intergroup relational identity in an organization having employees with interdependent rather than independent self-construals. On the other hand, the opposite may be the case if the boundaries of interdependence map onto group boundaries, and so this remains an open question for future research to explore.
The implications of our analysis are not limited to intergroup relations in organizations. Indeed, intergroup relations research has been more involved with societal than organizational intergroup relations, and an important question from the perspective of intergroup relations research would be how the concept of intergroup relational identity may inform and complement social identity analyses of societal intergroup relations. One obvious direction to take is the study of intergroup leadership in the political or national context, where leadership is often faced with the challenge of building bridges across political, ethnic, and cultural divides.

For example, the speeches of President Nelson Mandela around the 2007 Rugby World Championship in South Africa provide a powerful illustration of intergroup leadership through building intergroup relational identity. The history of ethnic conflict in South Africa precluded any attempts to appeal to similarity within a shared superordinate identity, and so Mandela emphasized the partnership of different and distinct ethnic groups in building a post-apartheid South Africa.

However, some caution should be exercised in widening the scope of the present analysis that focuses on leadership of collaborations of formal organizational groups targeted at the achievement of joint outcomes. For example, in situations where intergroup collaboration is less focal, our analysis may not apply or may apply only in a modified form. Extension or application beyond the scope of our analysis as intended here should pay close attention to differences between the contexts targeted in the current analysis and the context in which the analysis would be applied.

Research testing our propositions regarding intergroup leadership would also be important for the translation of our analysis to leadership practice-for instance, in leadership development programs. Whereas at a certain level of abstraction the implications for practice of our propositions are straightforward-after all, they concern what leaders should do to build effective intergroup collaborations-the skills needed to convey the appropriate intergroup relational message by using compelling identity rhetoric and by building boundary-spanning relationships may not be easy to master. Empirical research testing and developing our analysis may thus also be important in developing 
the knowledge base to support the development of intergroup leadership-for instance, by yielding a body of illustrative case studies of the kind of rhetoric that is effective in building intergroup relational identity. Clearly, the application of these insights in leadership development would require study in its own right to determine how these intergroup identity skills can be developed in leaders, but the empirical development of our analysis should provide important guidance for these research efforts targeted at leadership development.

The challenge in further developing the analysis of intergroup leadership, therefore, is twofold. First, we need systematic empirical research to corroborate and extend the current propositions to provide a strong foundation for evidence-based management, as well as the continued study of intergroup leadership and intergroup relations in organizations more generally. Second, we need a concentrated effort to translate the current propositions in combination with emerging research findings into concrete implications for leadership practicetraining and development. Through such efforts we may help leadership research and practice speak to one of the greater leadership challenges: working across group boundaries.

\section{REFERENCES}

Abrams, D., \& Hogg, M. A. 2010. Social identity and selfcategorization. In J. F. Dovidio, M. Hewstone, P. Glick, \& V. M. Esses (Eds.), The Sage handbook of prejudice, stereotyping and discrimination: 179-193. London: Sage.

Alderfer, C. P. 1997. Embedded intergroup relations and racial identity theory. In C. E. Thompson \& R. T. Carter (Eds.), Applications of racial identity development theory: Individual, group, and organizational interventions: 237-263. Hillsdale, NJ: Lawrence Erlbaum Associates.

Alderfer, C. P. 2010. The practice of organizational diagnosis: Theory and methods. New York: Oxford University Press.

Alderfer, C. P., \& Smith, K. K. 1982. Studying intergroup relations embedded in organizations. Administrative Science Quarterly, 27: 35-65.

Andersen, S. M., \& Chen, S. 2002. The relational self: An interpersonal social-cognitive theory. Psychological Review, 109: 619-645.

Asshforth, B. E., \& Mael, F. A. 1989. Social identity theory and the organization. Academy of Management Review, 14: 20-39.

Bass, B. M. 1985. Leadership and performance beyond expectations. New York: Free Press.

Bass, B. M. 1990. Bass and Stogdill's handbook of leadership (3rd ed.). New York: Free Press.
Berg, D. N. 2005. Senior executive teams: Not what you think. Consulting Psychology Journal, 57: 107-117.

Blake, R. P., Shepard, H. A., \& Mouton, J. S. 1964. Managing intergroup conflict in industry. Houston: Gulf Publishing.

Brett, J. M., \& Rognes, J. K. 1986. Intergroup relations in organizations. In P. S. Goodman (Ed.), Designing effective work groups: 202-236. San Francisco: Jossey-Bass.

Brewer, M. B. 1991. The social self: On being the same and different at the same time. Personality and Social Psychology Bulletin, 17: 475-482.

Brewer, M. B. 2001. The many faces of social identity: Implications for political psychology. Political Psychology, 22: 115-125.

Brewer, M. B., \& Brown, R. J. 1998. Intergroup relations. In D. T. Gilbert, S. T. Fiske, \& G. Lindzey (Eds.), The handbook of social psychology (4th ed.), vol. 2: 554-594. New York: McGraw-Hill.

Brewer, M. B., \& Gardner, W. 1996. Who is this "we"? Levels of collective identity and self representation. Journal of Personality and Social Psychology, 71: 83-93.

Brickson, S. L. 2000. The impact of identity orientation on individual and organizational outcomes in demographically diverse settings. Academy of Management Review, 25: 82-101.

Callister, R. R., \& Wall, J. A., Jr. 2001. Conflict across organizational boundaries: Managed care organizations versus health care providers. Journal of Applied Psychology, 86: 170-181.

Cartwright, S., \& Schoenberg, R. 2006. Thirty years of mergers and acquisitions research: Recent advances and future opportunities. British Journal of Management, 17: Sl-S5.

Chen, S., Boucher, H. C., \& Tapias, M. P. 2006. The relational self revealed: Integrative conceptualization and implications for interpersonal life. Psychological Bulletin, 132: 151-179.

Cohen, S. G., \& Bailey, D. E. 1997. What makes teams work: Group effectiveness research from the shop floor to the executive suite. Journal of Management, 23: 239-290.

Conger, J. A., \& Kanungo, R. N. 1987. Toward a behavioral theory of charismatic leadership in organizational settings. Academy of Management Review, 12: 637-647.

Crocker, J., Major, B., \& Steele, C. 1998. Social stigma. In D. T. Gilbert, S. T. Fiske, \& G. Lindzey (Eds.), The handbook of social psychology (4th ed.), vol. 2: 504-553. New York: McGraw-Hill.

Crosby, B. C., \& Bryson, J. M. 2010. Integrative leadership and the creation and maintenance of cross-sector collaborations. Leadership Quarterly, 21: 211-320.

Dalton, M., \& Chrobot-Mason, D. 2007. A theoretical exploration of manager and employee social identity, cultural values and identity conflict management. International Journal of Cross Cultural Management, 7: 169-183.

Davies, K., Tropp, L. R., Aron, A., Pettigrew, T. F., \& Wright, S. C. 2011. Cross-group friendships and intergroup atti- 
tudes: A meta-analytic review. Personality and Social Psychology Review, 15: 332-351.

Day, D. V., Gronn, P., \& Salas, E. 2004. Leadership capacity in teams. Leadership Quarterly, 15: 857-880.

Dovidio, J. F., \& Gaertner, S. L. 2010. Intergroup bias. In S. T. Fiske, D. T. Gilbert, \& G. Lindzey (Eds.), Handbook of social psychology (5th ed.), vol. 2: 1084-1121. New York: Wiley.

Duck, J. M., \& Fielding, K. S. 2003. Leaders and their treatment of subgroups: Implications for evaluations of the leader and the superordinate group. European Journal of Social Psychology, 33: 387-401.

Dutton, J. E., Dukerich, J. M., \& Harquail, C. V. 1994. Organizational images and membership commitment. Administrative Science Quarterly, 39: 239-263.

Elsbach, K. D., \& Bhattacharya, C. B. 2001. Defining who you are by what you're not: Organizational disidentification and the National Rifle Association. Organization Science, 12: 393-413.

Ernst, C., \& Yip, J. 2009. Boundary-spanning leadership: Tactics to bridge social identity groups in organizations. In T. Pittinsky (Ed.), Crossing the divide: Intergroup leadership in a world of difference: 87-99. Cambridge, MA: Harvard Business Publishing.

Gaertner, S. L., \& Dovidio, J. F. 2000. Reducing intergroup bias: The common ingroup identity model. New York: Psychology Press.

Gaertner, S. L., Mann, J., Murrell, A., \& Dovidio, J. F. 1989. Reducing intergroup bias: The benefits of recategorization. Journal of Personality and Social Psychology, 57: 239-249.

Gannon, M. J., \& Newman, K. L. (Eds.). 2002. The Blackwell handbook of cross-cultural management. Oxford: Blackwell.

Graen, G. B., \& Uhl-Bien, M. 1995. Relationship-based approach to leadership: Development of leader-member exchange (LMX) theory of leadership over 25 years: Applying a multi-level multi-domain approach. Leadership Quarterly, 6: 219-247.

Hackman, J. R., \& Wageman, R. 2005. When and how team leaders matter. Research in Organizational Behavior, 26 : 37-74.

Hambrick, D. C., Li, J., Xin, K., \& Tsui, A. S. 2001. Compositional gaps and downward spirals in international joint venture groups. Strategic Management Journal, 22: 10331053.

Heine, S. J. 2010. Cultural psychology. In S. T. Fiske, D. T. Gilbert, \& G. Lindzey (Eds.), Handbook of social psychology (5th ed.), vol. 2: 1423-1464. New York: Wiley.

Hewstone, M. 1996. Contact and categorization: Social psychological interventions to change intergroup relations. In C. N. Macrae, C. Stangor, \& M. Hewstone (Eds.), Stereotypes and stereotyping: 323-368. New York: Guilford Press.

Hewstone, M. R. C., \& Brown, R. J. 1986. Contact is not enough: An intergroup perspective on the contact hypothesis. In M. R. C. Hewstone \& R. J. Brown (Eds.), Contact and conflict in intergroup encounters: 1-44. Oxford: Blackwell.

Hogg, M. A. 2001. A social identity theory of leadership. Personality and Social Psychology Review, 5: 184-200.

Hogg, M. A. 2006. Social identity theory. In P. J. Burke (Ed.), Contemporary social psychological theories: 111-136. Palo Alto, CA: Stanford University Press.

Hogg, M. A. 2008. Social identity theory of leadership. In C. L. Hoyt, G. R. Goethals, \& D. R. Forsyth (Eds.), Leadership at the crossroads. Volume 1: Leadership and psychology: 62-77. Westport, CT: Praeger.

Hogg, M. A., \& Reid, S. A. 2006. Social identity, selfcategorization, and the communication of group norms. Communication Theory, 16: 7-30.

Hogg, M. A., \& Smith, J. R. 2007. Attitudes in social context: A social identity perspective. European Review of Social Psychology, 18: 89-131.

Hogg, M. A., \& Terry, D. J. 2000. Social identity and selfcategorization processes in organizational contexts. Academy of Management Review, 25: 121-140

Hogg, M. A., \& van Knippenberg, D. 2003. Social identity and leadership processes in groups. Advances in Experimental Social Psychology, 35: 1-52.

Hornsey, M. J., \& Hogg, M. A. 2000. Assimilation and diversity: An integrative model of subgroup relations. Personality and Social Psychology Review, 4: 143-156.

House, R. J. 1977. A 1976 theory of charismatic leadership. In J. G. Hunt \& L. L. Larson (Eds). Leadership: The cutting edge: 189-207. Carbondale: Southern Illinois University Press.

Ilgen, D. R., Hollenbeck, J. R., Johnson, M., \& Jundt, D. 2005. Teams in organizations: From I-P-O models to IMOI models. Annual Review of Psychology, 56: 517-544.

Johnson, R. E., Selenta, C., \& Lord, R. G. 2006. When organizational justice and the self-concept meet. Organizational Behavior and Human Decision Processes, 99: 175201.

Judge, T. A., Bono, J. E., Ilies, R., \& Gerhardt, M. W. 2002. Personality and leadership: A qualitative and quantitative review. Journal of Applied Psychology, 87: 765-780.

Judge, T. A., Piccolo, R. F., \& Ilies, R. 2004. The forgotten ones?: A re-examination of consideration, initiating structure, and leadership effectiveness. Journal of Applied Psychology, 89: 36-51.

Kaiser, R. B., Hogan, R., \& Craig, S. B. 2008. Leadership and the fate of organizations. American Psychologist, 63: $96-$ 110.

Kearney, E., \& Gebert, D. 2009. Managing diversity and enhancing team outcomes: The promise of transformational leadership. Journal of Applied Psychology, 94: 7789.

Kessler, T., \& Hollbach, S. 2005. Group-based emotions as determinants of ingroup identification. Journal of Experimental Social Psychology, 41: 677-685.

King, D. R., Dalton, D. R., Daily, C. M., \& Covin, J. G. 2004. Meta-analysis of post-acquisition performance: Indica- 
tions of unidentified moderators. Strategic Management Journal, 25: 128-151.

Kramer, R. 1991. Intergroup relations and organizational dilemmas. Research in Organizational Behavior, 13: 191228.

Li, J., \& Hambrick, D. C. 2005. Factional groups: A new vantage on demographic faultlines, conflict, and disintegration in work teams. Academy of Management Journal, 48: 794-813.

Lord, R. G., \& Brown, D. J. 2004. Leadership processes and follower identity. Mahwah, NJ: Lawrence Erlbaum Associates.

Lord, R. G., Brown, D. J., \& Freiberg, S. J. 1999. Understanding the dynamics of leadership: The role of follower selfconcepts in the leader/follower relationship. Organizational Behavior and Human Decision Processes, 78: 167203.

Mackie, D. M., Maitner, A. T., \& Smith, E. R. 2009. Intergroup emotions theory. In T. D. Nelson (Ed.), Handbook of prejudice, stereotyping and discrimination: 285-308. New York: Psychology Press.

Mael, F. A., \& Ashforth, B. E. 1992. Alumni and their alma mater: A partial test of the reformulated model of organizational identification. Journal of Organizational Behavior, 13: 103-123.

Markus, H., \& Kitayama, S. 1991. Culture and the self: Implications for cognition, emotion, and motivation. Psychological Review, 98: 224-253.

Mathieu, J. E., Cobb, M. A., Marks, M. A., Zaccaro, S. J., \& Marsh, S. 2004. Multi-team ACES: A research platform for studying multi-team systems. In S. G. Schiflett, L. R. Elliott, E. Salas, \& M. Coovert (Eds.), Scaled worlds: Development, validation and applications: 297-315. Burlington, VT: Ashgate.

Mohammed, S., Hamilton, K., \& Lim, A. 2009. The incorporation of time in team research: Past, current, and future. In E. Salas, G. F. Goodwin, \& C. S. Burke (Eds.), Team effectiveness in complex organizations: Cross-disciplinary perspectives and approaches: 321-348. New York: Routledge, Taylor and Francis Group.

Mohrman, S. A., Cohen, S. G., \& Mohrman, A. M. 1995. Designing team-based organizations: New forms for knowledge work. San Francisco: Jossey-Bass.

Mummendey, A., \& Wenzel, M. 1999. Social discrimination and tolerance in intergroup relations: Reactions to intergroup difference. Personality and Social Psychology Review, 3: 158-174.

Oaker, G., \& Brown, R. J. 1986. Intergroup relations in a hospital setting: A further test of social identity theory. Human Relations, 39: 767-778.

Oh, H., Chung, M. H., \& Labianca, G. 2004. Group social capital and group effectiveness: The role of informal socializing ties. Academy of Management Journal, 47: 860-875.

Ospina, S., \& Foldy, E. 2010. Building bridges from the margins: The work of leadership in social change organizations. Leadership Quarterly, 21: 292-307.
Pearce, C. L., \& Sims, H. P., Jr. 2000. Shared leadership: Toward a multi-level theory of leadership. Advances in the Interdisciplinary Studies of Work Teams, 7: 115-139.

Pfeffer, J., \& Salancik, G. R. 1977. Organization design: The case for a coalitional model of organizations. Organizational Dynamics, 6(4): 15-29.

Pittinsky, T. (Ed.). 2009. Crossing the divide: Intergroup leadership in a world of difference. Cambridge, MA: Harvard Business Publishing.

Pittinsky, T. L., \& Simon, S. 2007. Intergroup leadership. Leadership Quarterly, 18: 586-605.

Platow, M. J., \& van Knippenberg, D. 2001. A social identity analysis of leadership endorsement: The effects of leader ingroup prototypicality and distributive intergroup fairness. Personality and Social Psychology Bulletin, 27: 1508-1519.

Ployhart, R. E., \& Vandenberg, R. J. 2010. Longitudinal research: The theory, design, and analysis of change. Journal of Management, 36: 94-120.

Pondy, L. R. 1967. Organizational conflict: Concepts and models. Administrative Science Quarterly, 12: 296-320.

Reicher, S. D., \& Hopkins, N. 2003. On the science of the art of leadership. In D. van Knippenberg \& M. A. Hogg (Eds.), Leadership and power: Identity processes in groups and organizations: 197-209. London: Sage.

Richter, A. W., West, M. A., van Dick, R., \& Dawson, J. F. 2006. Boundary spanners' identification, intergroup contact, and effective intergroup relations. Academy of Management Journal, 49: 1252-1269.

Ritter, B. A., \& Lord, R. G. 2007. The impact of previous leaders on the evaluation of new leaders: An alternative to prototype matching. Journal of Applied Psychology, 92: 1683-1695.

Rutchick, A. M., \& Eccleston, C. P. 2010. Ironic effects of invoking a common ingroup identity. Basic and Applied Social Psychology, 32: 109-117.

Seyranian, V., \& Bligh, M. C. 2008. Presidential charismatic leadership: Exploring the rhetoric of social change. Leadership Quarterly, 19: 54-76.

Shamir, B., House, R., \& Arthur, M. B. 1993. The motivational effects of charismatic leadership: A self-concept based theory. Organization Science, 4: 577-594.

Shamir, B., Zakay, E., Breinin, E., \& Popper, M. 1998. Correlates of charismatic leader behavior in military units: Subordinates' attitudes, unit characteristics, and superiors' appraisals of leader performance. Academy of Management Journal, 41: 387-409.

Shin, S. J., \& Zhou, J. 2007. When is educational specialization heterogeneity related to creativity in research and development teams? Transformational leadership as a moderator. Journal of Applied Psychology, 92: 1709-1721.

Singelis, T. M. 1994. The measurement of independent and interdependent self-construals. Personality and Social Psychology Bulletin, 20: 580-591.

Sluss, D. M., \& Ashforth, B. E. 2007. Relational identity and identification: Defining ourselves through work relationships. Academy of Management Review, 32: 9-32. 
Sluss, D. M., \& Ashforth, B. E. 2008. How relational and organizational identification converge: Processes and conditions. Organization Science, 19: 807-823.

Sluss, D. M., Klimchak, M., \& Holmes, J. J. 2008. Perceived organizational support as a mediator between relational exchange and organizational identification. Journal of Vocational Behavior, 73: 457-464.

Sluss, D. M., van Dick, R., \& Thompson, B. S. 2010. Role theory in organizations: A relational perspective. In S. Zedeck (Ed.), APA handbook of industrial and organizational psychology, vol. 1: 505-534. Washington, DC: American Psychological Association.

Smith, P. B., \& Peterson, M. F. 2002. Cross-cultural leadership. In M. J. Gannon \& K. L. Newman (Eds.), The Blackwell handbook of cross-cultural management: 217-235. Oxford: Blackwell.

Tajfel, H., \& Turner, J. C. 1979. An integrative theory of intergroup conflict. In W. G. Austin \& S. Worchel (Eds.), The social psychology of intergroup relations: 33-47. Monterey, CA: Brooks/Cole.

Thomas, D. C. 2008. Cross-cultural management: Essential concepts (2nd ed.). Thousand Oaks, CA: Sage.

Thompson, L. L. 2009. The mind and heart of the negotiator (4th ed.). Upper Saddle River, NJ: Prentice-Hall.

Turner, J. C. 1991. Social influence. Milton Keynes, UK: Open University Press.

Turner, J. C., Hogg, M. A., Oakes, P. J., Reicher, S. D., \& Wetherell, M. S. 1987. Rediscovering the social group: $A$ self-categorization theory. Oxford: Blackwell.

Ullrich, J., \& van Dick, R. 2007. The group psychology of mergers and acquisitions. In C. L. Cooper \& S. Finkelstein (Eds.), Advances in mergers and acquisitions, vol. 6: 1-15. Bingley, UK: Emerald.

van Ginkel, W. P., \& van Knippenberg, D. In press. Group leadership and shared task representations in decisionmaking groups. Leadership Quarterly.

van Knippenberg, D. 2000. Work motivation and performance: A social identity perspective. Applied Psychology, 49: 357-371.

van Knippenberg, D. 2003. Intergroup relations in organizations. In M. West, D. Tjosvold, \& K. G. Smith (Eds.), International handbook of organizational teamwork and cooperative working: 381-399. Chichester, UK: Wiley.

van Knippenberg, D., De Cremer, D., \& van Knippenberg, B. 2007. Leadership and fairness: The state of the art. European Journal of Work and Organizational Psychology, 16: 113-140. van Knippenberg, D., \& Hogg, M. A. 2003. A social identity model of leadership in organizations. Research in Organizational Behavior, 25: 243-295.

van Knippenberg, D., \& Schippers, M. C. 2007. Work group diversity. Annual Review of Psychology, 58: 515-541.

van Knippenberg, D., van Knippenberg, B., \& Bobbio, A. 2008. Leaders as agents of continuity: Self continuity and resistance to collective change. In F. Sani (Ed.), Selfcontinuity: Individual and collective perspectives: 175186. New York: Psychology Press.

van Knippenberg, D., van Knippenberg, B., De Cremer, D., \& Hogg, M. A. 2004. Leadership, self, and identity: A review and research agenda. Leadership Quarterly, 15: 825-856.

van Knippenberg, D., van Knippenberg, B., Monden, L., \& de Lima, F. 2002. Organizational identification after a merger: A social identity perspective. British Journal of Social Psychology, 41: 233-252.

Wageman, R., \& Hackman, J. R. 2010. What makes teams of leaders leadable? In N. Nohria \& R. Kuhrana (Eds.), Advancing leadership: 457-487. Boston: Harvard Business School Press.

Wageman, R., Nunes, D. A., Burruss, J. A., \& Hackman, J. R. 2008. Senior leadership teams: What it takes to make them great. Boston: Harvard Business School Press.

Weick, K. E. 1993. The collapse of sensemaking in organizations: The Mann Gulch disaster. Administrative Science Quarterly, 38: 628-652.

Wenzel, M., Mummendey, A., Weber, U., \& Waldzus, S. 2003. The ingroup as pars pro toto: Projection from the ingroup onto the inclusive category as a precursor to social discrimination. Personality and Social Psychology Bulletin, 29: $461-473$.

Williams, K., \& O’Reilly, C. 1998. Demography and diversity in organizations: A review of 40 years of research. Research in Organizational Behavior, 20: 77-140.

Wittgenstein, L. 1953. Philosophical investigations. Oxford: Blackwell.

Wright, S. C., Aron, A., McLaughlin-Volpe, T., \& Ropp, S. A. 1997. The extended contact effect: Knowledge of crossgroup friendships and prejudice. Journal of Personality and Social Psychology, 73: 73-90.

Wright, S. C., Aron, A., \& Tropp, L. R. 2002. Including others (and their groups) in the self: Self-expansion and intergroup relations. In J. P. Forgas \& K. Williams (Eds.), The social self: Cognitive, interpersonal and intergroup perspectives: 343-363. New York: Psychology Press.

Yukl, G. 2010. Leadership in organizations (7th ed.). Upper Saddle River, NJ: Prentice-Hall.

Michael A. Hogg (michael.hogg@cgu.edu) is professor of social psychology at Claremont Graduate University, president-elect of the Society of Experimental Social Psychology, and a fellow of the Association for Psychological Science. He has a Ph.D. from Bristol University. His research on social identity, group processes, and intergroup relations has a focus on influence and leadership and uncertainty and extremism.

Daan van Knippenberg (dvanknippenberg@rsm.nl) is professor of organizational behavior, Rotterdam School of Management, Erasmus University Rotterdam; director and cofounder of the Erasmus Centre for Leadership Studies; and a fellow of the Society for 
Industrial and Organizational Psychology. He has a Ph.D. from Leiden University. His research interests include leadership, diversity, creativity, and social identity.

David E. Rast, III (david.rast@cgu.edu) is a doctoral candidate in social psychology at Claremont Graduate University and a Consortium Research Fellow at the Army Research Institute at Fort Leavenworth, Kansas. He studies the effects of social identity processes and phenomena, with a focus on leadership, influence, and persuasion. 